\title{
The coupling of reversed-phase HPLC with ICP MS in bioinorganic analysis
}

\author{
H. Chassaigne and J. Szpunar \\ CNRS EP132, Université de Pau et des Pays de l'Adour, Hélioparc, 2 avenue du Président Angot, 64000 Pau, France
}

\begin{abstract}
The coupling of reversed-phase HPLC with ICPMS offers an attractive orthogonal approach to size-exclusion HPLC-ICP-MS for the characterisation of complex bioinorganic systems. An interface between microbore RP-HPLC and ICPMS using a direct injection nebulizer which allows the introduction of mobile phases up to $50 \%$ methanol is described. Its applications for the analysis of cobalamins and metallothioneins are illustrated.
\end{abstract}

$\mathrm{T}$ he complexity of many naturally existing classes of bioinorganic species makes the resolution of sizeexclusion chromatography insufficient for a more detailed characterisation (within a given class) of the metal complexes present. It is well known that some species with essentially similar molecular masses may show some structural differences which may be crucial for their role in life processes. Therefore, despite SEC-ICP-MS being the primary technique for the detection of metal species in natural samples [1], the compounds detected by this technique should be further examined by chromatographic or electrophoretic techniques with complementary separation mechanisms.

Whereas in the case of SEC the coupling with ICP-MS is readily achieved owing to the compatibility of the mobile phase composition and flow-rates used, the use of ICP-MS as a detector in RP-HPLC with gradient elution using mobile phases containing more than $20 \%$ of an organic solvent have been relatively scarce because of the low tolerance of the plasma to the solvent vapour [2-12]. Only two applications concerned metalloproteins [3,12]. Although the ICP mass spectrometer used in this work can tolerate the introduction of $50 \%$ or more aqueous methanol in the FIA mode $\left(100 \mu \mathrm{L}\right.$ injection into an aqueous stream of $\left.1 \mathrm{~mL} \mathrm{~min}{ }^{-1}\right)$, experiments showed that concentrations of methanol above $15 \%$ in the mobile phase pumped continuously at $1 \mathrm{~mL}$ $\mathrm{min}^{-1}$ lead to the extinction of the plasma within a few minutes rendering the acquisition of a chromatogram impossible [12].

High levels of organic solvents in the mobile phase can be coped with by using a refrigerated spray chamber [5-7] or a nebulizer with a desolvation unit [8-11]. An elegant way to overcome the incompatibility of the mobile phase composition with the ICP is a post-column dilution of the effluent to bring the concentration of methanol to a level tolerated by the plasma. An interface between microbore HPLC and ICP-MS based on this principle and examples of its applications are presented below.

\section{Description of the interface}

The interface developed is shown in figure 1. It is based on the use of a direct injection nebulizer (DIN). The DIN is a microconcentric nebulizer with no spray chamber; it nebulizes the liquid sample directly into the central channel of the ICP torch [13]. Compared with conventional nebulizers it offers $100 \%$ sample introduction efficiency into the ICP, accomodation of low sample introduction flow rates $(10-$ $\left.100 \mu \mathrm{L} \mathrm{min}{ }^{-1}\right)$, an extremely small internal volume $(<2 \mu \mathrm{L})$ and fast sample washout with minimal memory effects.

The use of the DIN eliminates the basic problem of the conventional nebulizers to couple micro or narrowbore chromatography with ICP-MS as the use of a microbore column (flow rate of $40 \mu \mathrm{L} \mathrm{min}-1$ ) would require a makeup flow of 20 times higher to match the working range of a cross-flow or concentric nebulizer $(0.6-1 \mathrm{~mL})$. This would lead to a 


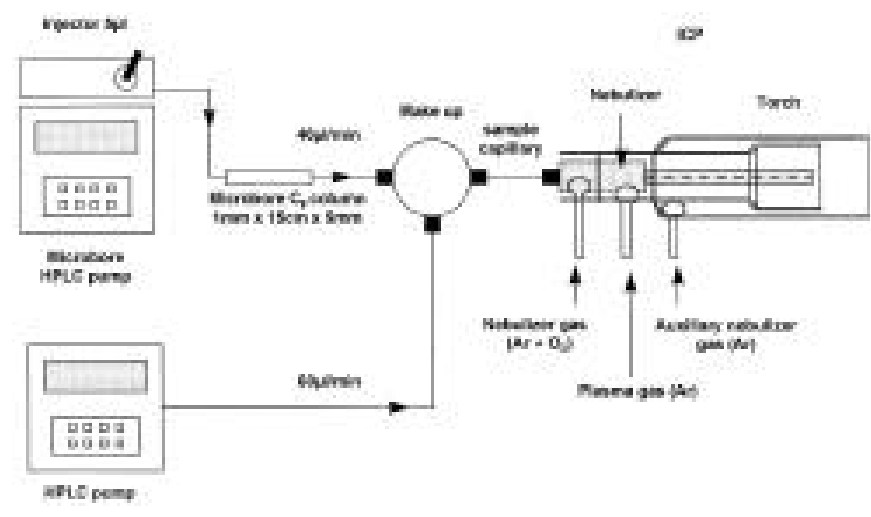

Figure 1.Scheme of the interface enabling the use of high organic solvent percentage in mobile phase for the coupling of microbore reversed-phase HPLC-ICP-MS.

considerable dilution and high post-column dead volume to which the contribution of the spray chamber should be taken into account. In the case of the DIN the dilution factor is 2.5 which, on one hand, is sufficient to decrease the concentration of the organic modifier so that it does not make the plasma unstable, and, on the other hand, does not contribute much to the post-column dispersion and the loss of the number of the theoretical plates. Under the optimized conditions the sensitivity of the DIN-ICP-MS for the ${ }^{59} \mathrm{Co}$ nuclide was a factor of 2 lower than that obtained with the cross-flow nebulizer and corresponded to the manufacturer's (CETAC) specification. The relative standard deviation (for signals not limited by counting statistics) was $1-2 \%$.

\section{Species selective analysis of cobalamin analogues}

Cobalamins are coenzymatically active forms of vitamin $\mathrm{B}_{12}$ (cyanocobalamin) which is a water-soluble vitamin and a nutrient essential for all cells $[14,15]$. They belong to the group of corrinoids which are composed of a corrin nucleus with a cobalt atom in its centre. The cobalt atom is coordinately linked to a nitrogen of a pendant 5,6-dimethylbenzimidazole group. The molecule also contains ribose with an $\alpha$-glycosidic linkage. Depending on the substituent of the cobalt atom (upper axial ligand) different forms of vitamin $\mathrm{B}_{12}$ : cyanocobalamin $(\mathrm{CN})$, adenosylcobalamin (coenzyme $\mathrm{B}_{12}$, 5'-desoxyadenosyl), methylcobalamin $\left(\mathrm{CH}_{3}\right)$, hydroxocobalamin $(\mathrm{OH})$ and aquocobalamin $\left(\mathrm{H}_{2} \mathrm{O}\right)$, exist. Cobalamins should be distinguished from their potentially harmful analogues devoid of enzymatic activity such as e.g., cobinamides that lack the nucleotide moiety (5,6-dimethylbenzimidazole). The monitoring of the intermediate and finished products of cobalamin drugs is essential for process and quality control. Analysis of multivitamin preparations for parental nutrition is required to evaluate the stability (aging) of corrinoid compounds to light exposure and temperature, and their interactions with other vitamins and trace elements.

A chromatogram obtained by microbore HPLC-DINICP-MS under the conditions optimized above is shown in
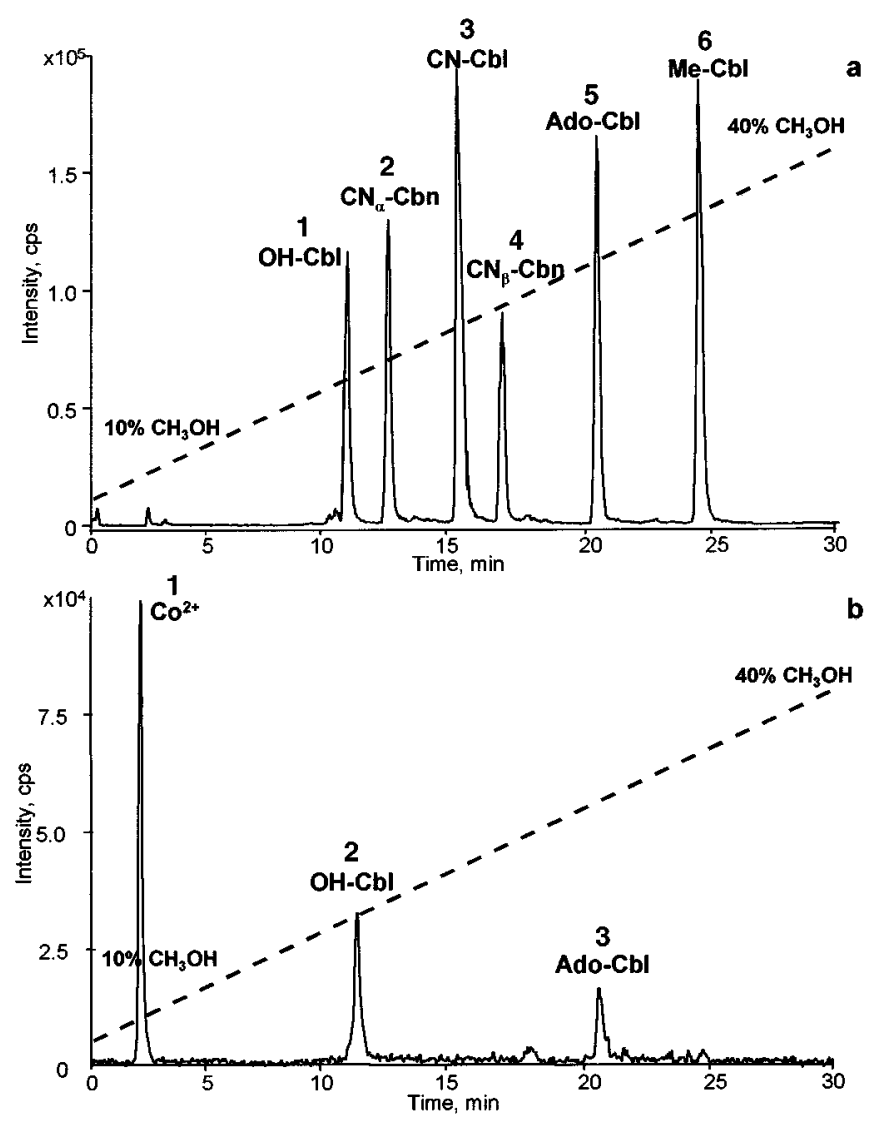

Figure 2. Analysis of cobalamin analogues by microbore (Vydac $\mathrm{C}_{8} 150 \mathrm{~mm} \times 1 \mathrm{~mm} \times 5 \mu \mathrm{m}$ ) HPLC - DIN - ICP MS. a) mixture of standards. 1 - hydroxocobalamin, 2 - $\mathrm{CN}-\alpha$-cobinamide, 3 - cyanocobalamin, 4 - CN- $\beta$-cobinamide, 5 - adenosylcobalamin, 6 methylcobalamin; b) pharmaceutical preparation. 1 - $\mathrm{Co}^{2+}$ (dead volume); 2 - hydroxocobalamin; 3 - adenosylcobalamin. Conditions: pH 4.0, injected volume $5 \mu \mathrm{L}$, each standard at $\mathbf{5 0}$ ng. The gradient profile is indicated in $\% \mathrm{CH}_{3} \mathrm{OH}$ by the dotted line.

figure 2a. Calibration curves are linear over three decades and the analytical precision varies between $2-5 \%$.

ICP-MS is an element selective detector which detects only Co which forms $5 \%$ of the total molecule. Nevertheless the detection limits obtained by microbore HPLC-DIN-ICPMS are about 100 times lower that those obtained with UV detection and are the lowest ever reported for on-line detection of cobalamins. The value of $20 \mathrm{ng} \mathrm{mL}^{-1}$ corresponds to an ADL of $0.1 \mathrm{ng}$ of a cobalamin and matches the detection limits normally determined off-line by radioisotope dilution. Microbore HPLC-DIN-ICP-MS is an attractive technique for the evaluation of the serum cobalamin status.

Figure $2 \mathrm{~b}$ shows the application of the method developed to the analysis of the status of a hydroxocobalamin preparation at detection levels not accessible by UV or ESI-MS. Two signals, in addition to the peak of $\mathrm{Co}^{2+}$ eluting with the dead volume, can be distinguished at retention times corresponding to hydroxocobalamin and adenosylcobalamin in a chromatogram obtained with DIN-ICP-MS. The concentrations determined using calibration by means of a standard graph were $1.11 \pm 0.03 \mu \mathrm{g} \mathrm{mL} \mathrm{L}^{-1}$ for $\mathrm{OH}-\mathrm{Cbl}$ (compared with the value of $1 \mu \mathrm{g} \mathrm{mL} \mathrm{m}^{-1}$ given by the manufacturer) and $473 \pm 6 \mathrm{ng} \mathrm{mL}^{-1}$ for Ado-Cbl. 


\section{Metal-selective analysis of metallothionein analogues}

Sequestration of metal ions (e.g. $\mathrm{Cd}^{2+}$ ) in stable, intracellular macromolecular complexes is a major mechanism by which cells resist the cytotoxic effects of the metal. Metallothioneins (MTs) [a group of non-enzymatic low molecular mass proteins $(6-7 \mathrm{kDa})]$ represent a class of the most common ligands. Classic techniques for the determination of MTs such as metal-saturation assays, polarography via sulfhydryl groups and immunoassays fail to provide information on the original metal composition and do not allow one to identify and to quantify the individual MT isoforms. The complexity of the polymorphism of mammalian metallothioneins and the variety of potentially bound metals $(\mathrm{Cd}, \mathrm{Zn}, \mathrm{Cu}, \mathrm{Hg})$ requires an approach coupling a high resolution separation technique able to distinguish between the proteins with a single aminoacid heterogeneity, and an element-selective detection technique able to determine the metals bound [16,17].

The developed coupling of microbore reversed-phase chromatography with ICP-MS was applied to a study of rabbit liver MT preparations isolated by size-exclusion chromatography and purified by anion-exchange chromatography to give the fractions of the two major isoforms: MT-1 and MT-2.

Chromatograms obtained under the optimum conditions are shown in figure 3. In contrast to the size-exclusion chromatograms of these MT-1 and MT-2 preparations which show one peak, the reversed-phase chromatograms are more complex. For MT-2 (Fig. 3a) the major peak apparently consists of three poorly resolved peaks and is accompanied by a noisy baseline and some minor peaks. One of these peaks can be identified according to its retention time as the $\mathrm{Cd}_{4}-\mathrm{MT}-2$ complex. HPLC-ICP-MS does not allow the attribution of the small peaks to labile $\mathrm{Cd}_{5}-\mathrm{MT}-2$ and $\mathrm{Cd}_{6}-$ MT-2 complexes or to different MT-2 sub-isoforms with microheterogeneities. A small copper peak (with an abundance corresponding to that calculated on the basis of the ratio of total $\mathrm{Cd}$ and $\mathrm{Cu}$ ) is present at the retention time of the major peak. The identity of the retention time suggests the presence of a mixed $\mathrm{Cd}-\mathrm{Cu}-\mathrm{MT}-2$ complex.

Figure $3 b$ shows an even more complex HPLC - DIN ICP-MS chromatogram of the other major MT isoform MT-1. Again it is not possible to state whether true sub-isoforms are involved or artefacts of differently metallated species of one isoform. The distribution of $\mathrm{Cu}$ among these isoform does not follow that of $\mathrm{Cd}$. Whether the early eluting peaks contain pure copper or mixed $\mathrm{Cd}-\mathrm{Cu}$ complexes remains to be elucidated. At this $\mathrm{pH}$ (6.0) $\mathrm{Zn}$ complexes are too labile to be separated.

\section{Conclusions}

The coupling of reversed-phase chromatography with ICPMS offers an attractive approach to examine the purity of a metal species isolated by size-exclusion chromatography. The use of an interface based on the post-column dilution of the methanolic mobile phase with water followed by
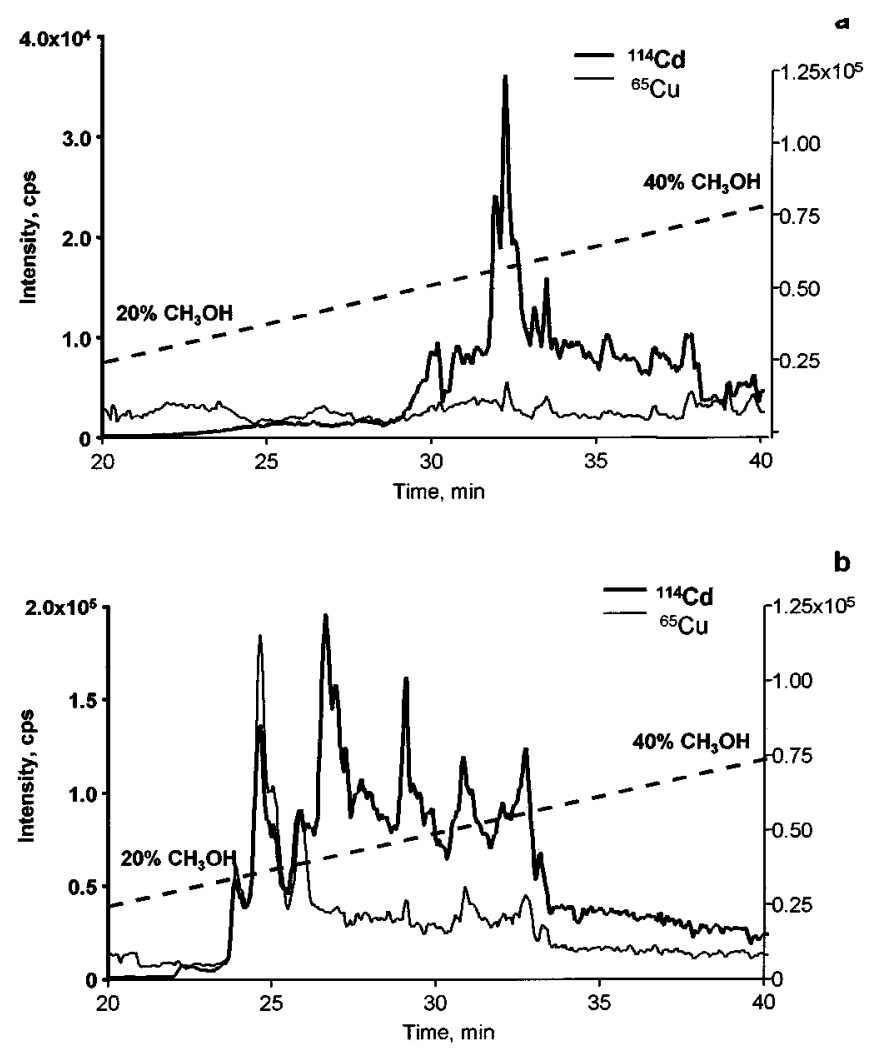

Figure 3. Analysis of MT preparations by microbore (Vydac $\mathrm{C}_{8}$ $150 \mathrm{~mm} \times 1 \mathrm{~mm} \times 5 \mu \mathrm{m}$ ) HPLC-DIN-ICP-MS. Conditions: $\mathrm{pH}$ 6.0, c.a. $50 \mathrm{ng}$ of MT injected. The dotted line indicates the $\mathrm{CH}_{3} \mathrm{OH}$ gradient used. Bold line $-{ }^{114} \mathrm{Cd}$, regular line $-{ }^{65} \mathrm{Cu}$. a) $\mathrm{MT}-2$, b) MT-1.

direct injection nebulization allows the use of microbore columns and the introduction of up to $50 \%$ methanol into an ICP. This is sufficient for the majority of studies of speciation and of the metallothioneins not only in terms of metals bound $(\mathrm{Cd}, \mathrm{Cu})$ but also in terms of iso- and sub-isoforms.

\section{References}

1. Makarov, A.; Szpunar, J. Analusis (this issue).

2. Thompson, J. J.; Houk, R. S. Anal. Chem. 1986, 58(12), 2541-2548.

3. Owen, L. M. W.; Crews, H. M.; Hutton, R. C.; Walsh, A. Analyst 1992, 117(3), 649-655.

4. Al-Rashdan, A.; Heitkemper, D.; Caruso, J. A. J. Chromatogr. Sci. 1991, 29, 98.

5. Vela, N. P.; Caruso, J. A. J. Anal. At. Spectrom. 1993, 8, 787.

6. Ding, H.; Olson, L. K.; Caruso, J. A. Spectrochim. Acta 1996, $51 B, 1801$.

7. Zhao, Z.; Jones, W. B.; Tepperman, K.; Dorsey, J. G.; Elder, R. C. J. Pharm. Biomed. Anal. 1992, 10(4), 279-287.

8. Yang, H. J.; Jiang, S. J.; Yang, Y. J.; Hwang, C. J. Anal. Chim. Acta 1995, 312(2), 141-148.

9. Jakubowski, N.; Thomas, C.; Stüwer, D.; Dettlaff, I.; Schram, J. J. Anal. At. Spectrom. 1996, 11, 1023.

10. Andrle, C. M.; Jakubowski, N.; Broekaert, J. A. C. Spectrochim. Acta Part. B 1997, 52B(2), 189-200.

11. Fairman, B.; Catterick, T.; Wheals, B.; Polinina, E. J. Chromatogr. A 1997, 758(1), 85-92. 
12. Szpunar, J.; Chassaigne, H.; Donard, O. F. X.; Bettmer, J.; Lobinski, R. in: Applications of Inductively Coupled Plasma Mass Spectrometry, Holland, G.; Tanner, S. Eds., RSC, Cambridge, 1997.

13. Wiederin, D. R.; Smith, F. G.; Houk, R. S. Anal. Chem. 1991, 63, 219.

14. Chassaigne, H.; Lobinski, R. Analyst 1998, 123, 131-137.
15. Chassaigne, H.; Lobinski, R. Anal. Chim. Acta 1998, 359(3), 227-235.

16. Chassaigne, H.; Lobinski, R. Fresenius'J. Anal. Chem. 1998, 361, 267.

17. Lobinski, R.; Chassaigne, H.; Szpunar, J. Talanta 1998, 46, 271-289. 